\title{
Do dissociative disorders exist in Northern Ireland?: Blind psychiatric - structured interview assessments of 20 complex psychiatric patients
}

\author{
Martin J. Dorahy, PhD, D. Clin. Psych* \\ Heather Mills, MRCPsych ${ }^{\star \star}$

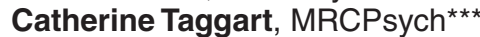

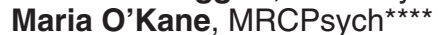 \\ Ciaran Mulholland, MRCPsych ${ }^{\star \star \star * *}$
}

* Trauma Resource Centre North \& West Belfast Health and Social Services Trust, Belfast, Northern Ireland

** Craigavon Psychiatric Unit

*** Department of Psychiatry, The Mater Hospital

**** Department of Psychiatry, Old See House, The Mater Hospital

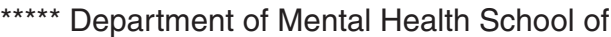
Medicine, The Queens University of Belfast

IRELAND

\begin{abstract}
Background and objectives: Dissociative disorders remain relatively controversial diagnoses in British psychiatry. The aim of the current paper was to assess Northern Irish psychiatric patients with complex clinical presentations for dissociative disorders.

Method: Twenty patients meeting operationally defined criteria for psychiatric complexity were blindly assessed by a psychiatrist in a diagnostic interview followed by a clinical psychologist in a structured interview.

Results: Thirteen of the 20 participants were positive for at least one dissociative disorder. Those with a dissociative disorder had a range of co-morbid problems and all reported histories of childhood trauma and neglect.

Conclusion: The psychiatric symptom profiles of dissociative disorders in Northern Ireland are similar to those reported in the literature. Complex psychiatric presentations offer a potential diagnostic clue for such conditions.
\end{abstract}




\section{Introduction}

British psychiatry has taken a relatively conservative and somewhat sceptical view of the modern study of dissociative identity disorder (DID). This view may be considerably different to the experience of a significant number of British practitioners ${ }^{1}$ and certainly diverges from the viewpoint of influential British clinicians and researchers working a century ago, who eagerly studied pathological dissociation (e.g., ${ }^{2}, \mathrm{see}^{3}$ ). The mental health system in Northern Ireland falls under the auspices of the British National Health Service and the training of psychiatrists and clinical psychologists is sanctioned and regulated by the Royal College of Psychiatry and the British Psychological Society, respectively. This study assessed the existence of dissociative disorders in complex psychiatric patients in Northern Ireland.

While pockets of scepticism exist in most psychiatric cultures regarding disorders like DID, a theme running through the historical dissociative disorders literature is that such conditions are not as rare as the psychiatric zeitgeist assumes. For example Prince ${ }^{4}$ noted in an early paper on Miss Beauchamp, that "cases of multiple personality are not very uncommon..." (p. 140). Similar sentiments were echoed many years later and before the empirical escalation of interest in dissociative disorders ${ }^{5}$. More recent studies, presenting large cases series of individuals with dissociative disorders (e.g., 6,7,8,9,10,11), add scientific weight to prior clinical assertions that dissociative disorders are more common than generally assumed. Further validation of this belief comes from studies of dissociative disorder prevalence in the psychiatric (e.g., ${ }^{12,13}$ ) and general ${ }^{14,15,16}$ populations.

European inpatient studies show prevalence estimates for dissociative disorders of between $4.5 \%$ to $8.2 \% 17,18,19,20^{1}$. DID prevalence in these same studies ranged from $.4 \%$ to $4.7 \%$. Factors such as the detection method used (e.g., which structured clinical interview is utilised) and the nature of the inclusion criteria set for individuals who receive thorough dissociative disorders assessment, effect prevalence figures (e.g., $\left.\operatorname{see}^{21}\right)$.

Coons $^{22}$ suggests that the underdiagnosis of dissociative disorders is related to scepticism in their existence and a failure to appreciate the actual prevalence rates of these conditions. Unfamiliarity with dissociative symptoms and diagnoses is also believed to contribute to detection failure of dissociative disorders $^{22,23}$. This latter factor may be particularly pertinent in clinical settings in Northern Ireland, as mental health professionals get little, if any, direct information on the phenomenology, prevalence, clinical characteristics and contemporary empirical understanding of dissociative disorders during training ${ }^{24}$. A further contributing difficulty in the detection of dissociative disorders is their often complex clinical presentations, which may include a complicated range of dissociative symptoms and other co-morbid and overlapping psychiatric and physical conditions ${ }^{6,25,26,27,28}$. For example, the positive or first rank symptoms of schizophrenia are typically present in DID, but may be mistaken as indicators of a psychotic illness ${ }^{29,30}$. Symptoms of anxiety, somatization, depression, posttraumatic stress, and various char-

1. Research by Sar and his Colleagues in Turkey have not been cited here to limit dissociative disorder prevalence studies to those conducted nearest the United Kingdom. 
acteristics of personality disorders are common in dissociative disorders ${ }^{10,31,32}$.

Studies have begun to address dissociative disorders in Northern Ireland, and clinicians' attitudes towards them. Dorahy and Lewis ${ }^{33}$ found that the existence of DID was generally accepted by Northern Irish clinicians (especially psychologists), but most believed the recent increase in prevalence was the result iatrogenesis and misdiagnosis, not accurate diagnosis. These explanations are consistent with viewpoints in the British ${ }^{34}$ and Irish $^{35}$ literatures. Only a very small number of Northern Irish clinicians $(n=9)$ had diagnosed or been involved in the treatment of DID. In a follow-on study, most Northern Irish psychiatrists and clinical psychologists failed to detect DID in a case where discriminating and characteristic symptoms and features were overt ${ }^{36}$.

The current study was designed to determined if DID and the other dissociative disorders actually exist in the Northern Irish psychiatric population. Psychiatric outpatients with complex psychiatric presentation were exclusively assessed using a thorough dissociative disorders assessment. Given empirical indications that dissociative disorders are not unusual in the psychiatric population, it was predicted that these conditions would be present in complex psychiatric patients in Northern Ireland.

\section{Method}

\section{Participants}

Based on the inclusion criteria outlined below (Procedure section), 21 adult psychiatric patients with no history of brain injury were identified for the study. While all agreed to take part, one withdrew, finding the assessment too emotionally taxing.

\section{Materials}

The psychiatric interview consisted of a diagnostic assessment of Axis 1 and 2 disorders and a developmental history, including experiences of life-time trauma. The structured interview assessment included the administration of the Dissociative Disorders Interview Schedule ${ }^{37}$ as well as the completion of the Dissociative Experiences Scale ${ }^{38}$ and the Somatoform Dissociation Questionnaire - $20\left(\right.$ SDQ-20, $\left.{ }^{39}\right)$.

The Dissociative Disorders Interview Schedule (DDIS) is a 132 item clinicianadministered structured interview for the detection of DSM-IV dissociative disorders. Related symptoms and diagnostic categories are also assessed, including those of Schneiderian symptoms, depression, borderline personality disorder, somatoform disorder and substance abuse. A section of the DDIS also assesses childhood physical and sexual abuse history. The DDIS has displayed good sensitivity for detecting true cases of DID ${ }^{40}$ and Kappa coefficients for detecting agreement between clinical judgement and DDIS indications of DID is over .9 (e.g. ${ }^{37}$ ). The current study omitted the DDIS abuse history items.

The Dissociative Experiences Scale (DES) contains 28 items believed to measure both non-pathological and pathological dissociation $^{41}$. Participants circle the percentage of time they experience each item on a scale ranging from $0 \%$ to $100 \%$. The eight items thought to best reflect pathological dissociation (items, $3,5,7,8,12,13,22,27$ ) are collectively referred to as the Dissociative Experiences Scale-Taxon (DES-T, ${ }^{41}$ ). The DES has a testretest reliability between .84 and .96 and an 
internal consistency of $.95^{42}$. Scores on both the DES and DES-T range from 0-100.

The Somatoform Dissociation Questionnaire - 20 (SDQ-20) is a 20 item self-report scale assessing somatoform dissociation. Experiences such as psychogenic anaesthesia, analgesia and loss of consciousness are appraised, along with disturbances in motor functioning and alterations in sensory perception. Items are rated along a Likert scale ranging from 1 ("this applies to me NOT AT ALL") to 5 ("this applies to me EXTREMELY"), with total scores ranging from 20 to 100. Having high correlations with psychoform measures of dissociation (e.g., DES) and an internal consistent (Cronbach's alpha) of .95 , the SDQ-20 has demonstrated good psychometric properties ${ }^{39,43}$.

\section{Procedure}

In the first instance two consultant psychiatrists (M.O'K; C.M) from the greater Belfast area assessed their adult caseload and selected patients who were deemed 'complex' based on meeting at least 2 of the following three operational defined criteria for psychiatric complexity:

- The patient had at least two different psychiatric diagnoses in their medical history.

- The patient was considered a "diagnostic anomaly": i.e., they did not "fit" one single psychiatric disorder, with their symptoms consistent with several diagnostic categories.

- The patient was "treatment-resistant" despite various interventions.

These criteria were developed from the clinical characteristics outlined in the dissociative disorders literature, especially that pertaining to DID (e.g., ${ }^{44}$ ). Towards the end of the study two other Belfast consul- tant psychiatrists referred individuals who met the inclusion criteria. Participants were informed that the study was assessing the psychological experience of dissociation, and if they volunteered they would attend two interviews spaced between a week and a month apart. Both referring psychiatrists were not treating any patients for dissociative disorders before the study started. In addition, with the exception of one patient who had just been accepted by one consultant with a query of dissociative disorder in their case history, both referring psychiatrists did not knowingly have any patients with dissociative disorders on their caseloads. Before the assessment phase began key phenomenological papers in the dissociative disorders literature were distributed to all clinicians involved in the study. These included papers by Coons, Kluft, Loewenstein, Putnam, Ross, Steinberg, and Van der Hart, Nijenhuis and Steele. Following familiarity with this literature both consultant psychiatrists re-examined the diagnoses given to those referred to the study.

Participants first attended the psychiatric assessment. This assessment, conducted by a psychiatrist (HM or CT) unaware of each participant's personal and psychiatric history, provided a diagnostic work-up indicating both differential and most likely diagnoses, along with a developmental history. The structured interview assessment, conducted by a clinical psychologist (MD) who was blind to the psychiatric assessment outcome and unaware of each patient's personal and psychiatric history, involved the administration of the DDIS, the DES and the SDQ. The DES was administered at the same time as the DDIS to determine if any individuals falling under traditional DES screening cutoff scores of 20-30, were actually positive for a dissociative disorder. Both the psychi- 
atric and structured interview assessments took approximately 1.5 hours.

A meeting was held at the completion of the study between the referring psychiatrists, the assessing psychiatrists and the clinical psychologist to discuss the diagnosis of each case. A dissociative disorder was not specified unless the clinical appraisal of at least 1 of the two psychiatrists involved in each case (i.e., either the patient's consultant psychiatrist, i.e., referring psychiatrist, or the assessing psychiatrist) was consonant with the structured interview indications. This strategy was deemed the most suitable means of minimising false positive diagnoses that may arise from using the DDIS in isolation ${ }^{21}$. Moreover, to provide the most conservative detection criteria, a DID diagnosis was only given when dissociative identities, and "switching" between them, were clearly observable during assessment.

ICD-10 is the psychiatric classification system primarily used on a day-to-day basis in Northern Ireland. Yet, all clinicians' involved in the study were familiar with the DSM system. Unlike the DSM-IV, the ICD10 does not classify depersonalisation disorder as a dissociative disorder. Given the DDIS was used (which is based on the DSM and therefore why DSM-IV classifications were utilised), depersonalisation disorder in the current study was classified as a dissociative disorder.

\section{Results}

The 20 participants who completed the study ranged in age from 26 - 57 years (Mean $=40.7 ; \mathrm{SD}=8.8)$. Nineteen were female and 18 were not working at the time of the study. Twelve participants were in relationships, 3 described themselves as 'single,' 4 reported being divorced or separated and 1 participant was widowed. One participant, recently transferred from a retiring psychiatrist to one of the referring psychiatrists, indicated that dissociative disorder had been mentioned to her in the past, but she was aware of no further details or what this meant. No other participant reported a dissociative disorder in their psychiatric history.

Thirteen $(65 \%)$ of the 20 assessed were positive for at least 1 dissociative disorder. The breakdown of these 13 positive cases were as follows: 1 DID, 2 depersonalisation disorder, 3 dissociative amnesia; 2 depersonalisation disorder and dissociative amnesia, and 5 DDNOS. Three individuals classified as DDNOS had strong self-report indications of DID but no switching between dissociative identities was observed during assessment. The assessing psychiatrist and clinical psychologist both independently diagnosed complex posttraumatic stress disorder for one other case, which due to the strict study criteria was not included as a dissociative disorder (and therefore was not among the 13 positive cases). On 2 of the 20 assessments, the DDIS and the clinical opinion of both the psychiatrists (consultant and assessing) did not match.

In order to present the clearest and most thorough explication of the clinical features of those meeting diagnostic and study criteria for a dissociative disorder, Table I individually presents each of the 13 dissociative cases along with co-morbid diagnoses, DDIS diagnostic indicators for the major conditions it assesses, as well as DES, DES-T and SDQ scores. For simple comparison purposes, summary and mean results for the 7 participants not positive for a dissociative disorder are included at the end of Table I. Due to the small number in this group no comparative statistics were used to assess differences 
between those with a dissociative disorder and the non-dissociative group.

Table II presents the presence or absence of childhood abuse or neglect histories as well as other child and adult traumas for each dissociative participant. As in Table I, a frequency and percentage summary is provided for those with and without a dissociative disorder, for comparison purposes. Due to the small number of participants, especially in the non-dissociative disorder group, statistical comparisons were not attempted.

Table I

Dissociative and comorbid diagnoses, DDIS clinical indications and psychoform and somatoform dissociation for the individuals with a dissociative disorder $(n=13)$.

\begin{tabular}{|c|c|c|c|c|c|c|c|c|c|c|}
\hline & $\begin{array}{l}\text { Dissoc. } \\
\text { Diag. }\end{array}$ & Co-morbid & $\begin{array}{l}\text { DDIS } \\
\text { Somat. }\end{array}$ & $\begin{array}{c}\text { DDIS } \\
\text { Sub.Ab }\end{array}$ & $\begin{array}{l}\text { DDIS } \\
\text { Dep. }\end{array}$ & $\begin{array}{c}\text { DDIS } \\
\text { FRS }\end{array}$ & $\begin{array}{l}\text { DDIS } \\
\text { BPD }\end{array}$ & DES & DES-T & SDQ \\
\hline 1 & Amnesia & $\begin{array}{l}\text { BPD- } \\
\text { Depressive } \\
\text { features }\end{array}$ & 12 no & No & Yes & 2 & Yes & 19.8 & 8.8 & 1.3 \\
\hline 2 & Amnesia & MDD & 11 no & No & Yes & 1 & Yes & 42.1 & 43.8 & 2.3 \\
\hline 3 & Amnesia & MDD & 7 no & No & Yes & 0 & No & 27.8 & 22.5 & 0.5 \\
\hline 4 & Deperson. & HistrionPD & 18 yes & No & Yes & 1 & No & 14.3 & 8.8 & 1.5 \\
\hline 5 & Deperson. & BPD, MDD & 19 yes & No & Yes & 2 & Yes & 34.3 & 13.7 & 3.5 \\
\hline 6 & $\begin{array}{l}\text { Amnesia } \\
\text { Deperson. }\end{array}$ & Panic/agora. & 20 no & No & Yes & 1 & No & 41.4 & 50 & 2.0 \\
\hline 7 & $\begin{array}{l}\text { Amnesia } \\
\text { Deperson. }\end{array}$ & MDD & 17 no & No & Yes & 0 & No & 37.5 & 16.3 & 1.4 \\
\hline 8 & DID & & 14 no & No & Yes & 8 & Yes & 59.6 & 58.1 & 2.3 \\
\hline 9 & DDNOS & & 12 no & No & Yes & 5 & Yes & 40 & 35 & 1.3 \\
\hline 10 & DDNOS & $\begin{array}{c}\text { BPD; } \\
\text { Cannabis, } \\
\text { amphet. } \\
\text { Abuse }\end{array}$ & 14 yes & Yes & Yes & 7 & Yes & 30.5 & 30 & 1.5 \\
\hline 11 & DDNOS & Dysthym. & 17 no & Yes & Yes & 1 & No & 27.5 & 21.3 & 1.5 \\
\hline 12 & DDNOS & & 19 yes & No & Yes & 10 & Yes & 87.3 & 77.5 & 2.2 \\
\hline 13 & DDNOS & BPD & 17 no & Yes & Yes & 8 & Yes & 44.8 & 30 & 2.0 \\
\hline $\begin{array}{l}\text { Tot. } \\
\text { DD }\end{array}$ & & & $\begin{array}{l}15.5^{1} \\
4 / 13^{2}\end{array}$ & $\begin{array}{l}3 / 13^{2} \\
23 \%\end{array}$ & $\begin{array}{l}13 / 13^{2} \\
100 \%\end{array}$ & $3.5^{1}$ & $\begin{array}{l}8 / 13^{2} \\
62 \%\end{array}$ & $39.0^{1}$ & $32.0^{1}$ & $1.8^{1}$ \\
\hline $\begin{array}{l}\text { Tot. } \\
\text { Non } \\
\text { DD. }\end{array}$ & & & $\begin{array}{l}11^{1} \\
0 / 7^{3}\end{array}$ & $\begin{array}{c}1 / 7^{3} \\
14 \%\end{array}$ & $\begin{array}{c}7 / 7^{3} \\
100 \%\end{array}$ & $3.3^{1}$ & $\begin{array}{l}3 / 7^{3} \\
43 \%\end{array}$ & $31.1^{1,4}$ & $23.8^{1,4}$ & $1.4^{1}$ \\
\hline
\end{tabular}

DDIS Somat = DDIS somatisation subscale; DDIS Sub.Ab = DDIS substance abuse subscale; DDIS Dep = DDIS depression subscale; DDIS FRS = DDIS First Rank Symptoms subscale; DDIS BPD = DDIS borderline personality disorder subscale. Deperson. = depersonalisation disorder; $\mathrm{BPD}=$ Borderline Personality Disorder; MDD = Major Depressive Disorder; Amphet. Abuse = Amphetamine Abuse; Dysthym. = Dysthymic Disorder; Panic/agora. $=$ Panic disorder with agoraphobia. Tot DD $=$ total for those with dissociative disorder; Tot. Non DD $=$ Total for those with no dissociative disorder. ${ }^{1}=$ mean scores $;^{2}=$ number of positive cases as identified by the DDIS over the number of individuals with a dissociative disorder; ${ }^{3}=$ number of positive cases as identified by the DDIS over the number of individuals without a dissociative disorder; ${ }^{4}=$ The DES and DES-T scores for 1 non-dissociative participants, with psychotic disorder NOS were removed. This participant continued to have difficulty and misinterpreted many of the questions, despite several attempts to explain the response format. 
Table II

Self-reported childhood history of trauma for the individuals with a dissociative disorder $(\mathrm{n}=13)$.

\begin{tabular}{|c|c|c|c|c|c|c|c|}
\hline & $\begin{array}{l}\text { Dissoc. } \\
\text { Diag. }\end{array}$ & $\begin{array}{l}\text { Child sex. } \\
\text { abuse }\end{array}$ & $\begin{array}{c}\text { Child physical } \\
\text { Abuse }\end{array}$ & $\begin{array}{l}\text { Child emotional } \\
\text { abuse }\end{array}$ & $\begin{array}{l}\text { Child } \\
\text { neglect }\end{array}$ & $\begin{array}{l}\text { Other child } \\
\text { trauma }\end{array}$ & $\begin{array}{l}\text { Adult } \\
\text { trauma }\end{array}$ \\
\hline 1 & Amnesia & Yes & Yes & Yes & Yes & $\begin{array}{l}\text { Yes } \\
\text { S }\end{array}$ & Yes \\
\hline 2 & Amnesia & Yes & Yes & Yes & Yes & $\begin{array}{l}\text { Yes } \\
\text { S }\end{array}$ & Yes \\
\hline 3 & Amnesia & Yes & $?$ & Yes & Yes & $\begin{array}{c}\text { Yes } \\
\text { DV, S }\end{array}$ & $?$ \\
\hline 4 & Deperson. & Yes & Yes & ? & No & $\begin{array}{l}\text { Yes } \\
\text { DV }\end{array}$ & No \\
\hline 5 & Deperson. & Yes & Yes & Yes & Yes & $\begin{array}{c}\text { Yes } \\
\text { DV } \\
\text { M MI }\end{array}$ & $?$ \\
\hline 6 & $\begin{array}{l}\text { Amnesia } \\
\text { Deperson. }\end{array}$ & Yes & Yes & Yes & No & $\begin{array}{c}\text { Yes } \\
\text { M rape } \\
\text { DV }\end{array}$ & $?$ \\
\hline 7 & $\begin{array}{c}\text { Amnesia } \\
\text { Deperson. }\end{array}$ & No & No & Yes & $?$ & Yes & Yes \\
\hline 8 & DID & No & Yes & Yes & Yes & $\begin{array}{l}\text { Yes } \\
\text { (DV) }\end{array}$ & Yes \\
\hline 9 & DDNOS & No & No & Yes & Yes & $\begin{array}{l}\text { Yes } \\
\mathrm{S}\end{array}$ & Yes \\
\hline 10 & DDNOS & Yes & Yes & Yes & No & No & Yes \\
\hline 11 & DDNOS & Yes & Yes & Yes & Yes & $\begin{array}{l}\text { Yes } \\
\text { S }\end{array}$ & No \\
\hline 12 & DDNOS & $\begin{array}{c}\text { Yes } \\
\text { (stranger) }\end{array}$ & No & No & No & No & Yes \\
\hline 13 & DDNOS & Yes & Yes & Yes & Yes & $\begin{array}{l}\text { Yes } \\
\text { DV }\end{array}$ & Yes \\
\hline total & & $\begin{array}{l}11 / 13 \\
84.6 \%\end{array}$ & $\begin{array}{l}9 / 13 \\
69.2 \%\end{array}$ & $\begin{array}{l}11 / 13 \\
84.6 \%\end{array}$ & $\begin{array}{l}8 / 13 \\
61.5 \%\end{array}$ & $\begin{array}{l}11 / 13 \\
84.6 \%\end{array}$ & $\begin{array}{l}8 / 13 \\
61.5 \%\end{array}$ \\
\hline Non & & $4 / 7 *$ & $3 / 7$ & $3 / 7$ & $2 / 7$ & $4 / 7$ & $2 / 7$ \\
\hline Diss. & & $57.1 \%$ & $42.8 \%$ & $42.8 \%$ & $28.5 \%$ & $57.1 \%$ & $28.5 \%$ \\
\hline
\end{tabular}

$\mathrm{S}=$ separation from family in childhood (e.g., adopted, parental inpatient psychiatric admission; no contact with at least one parent following separation); DV = parental domestic violence; $\mathrm{M} \mathrm{MI}=$ Maternal mental illness; $\mathrm{M}$ rape $=$ Mother raped; ? = unclear after questioning; $*=1$ case related to rape at age 15 .

\section{Discussion}

Consistent with the hypothesis that dissociative disorders would be present in the Northern Irish mental health system, over half the outpatients assessed in this study were positive for at least 1 dissociative disorder. With the exception of dissociative fugue all DSM-IV-TR dissociative disorders were evident in Northern Irish psychiatric outpatients. Whilst fugue often appears as a symptom of more complex dissociative disorders, the failure to identify discrete cases of fugue (i.e., outside cases of DID or DDNOS) is consistent with its absence in studies of dissociative disorder frequency and prevalence (e.g., ${ }^{18,45,46,47}$ ) and is in keeping with the belief that dissociative 
fugue as a stand alone diagnosis is one of the rarest dissociative disorders ${ }^{22}$.

The high number of somatic symptoms affirmed by the dissociative disorder cohort is consistent with previous studies of dissociative individuals (e.g., ${ }^{9,10,48}$ ). The finding that all dissociative participants had comorbid depression as indicated by the DDIS and five out of the six individuals with DID or DDNOS were positive on the DDIS for BPD is consistent with other studies. For example, using both the DDIS and the SCID-D, Horen et $a l .{ }^{45}$ found that all individuals positive for a dissociative disorder also showed DDIS indications for major depression. Moreover, three of the four individuals with DID or DDNOS in Horen et al.' $\mathrm{s}^{45}$ study were positive for BPD. Sar et al. ${ }^{49}$ reported a high prevalence of dissociative disorders in those meeting criteria for BPD, and BPD has been reported as a relatively common comorbid diagnosis in cases of DID ${ }^{9}$. Interestingly however, there was some discrepancy in the current study between BPD as indicated by clinical judgment versus the DDIS. Eight of the 13 individuals positive for a dissociative disorder showed DDIS indications of BPD, yet BPD was clinically diagnosed in only four of these cases. It seems likely that when assessed outside a full clinical picture (i.e., in isolation) BPD may be over-identified by the DDIS. This issue is pertinent in dissociative disorders as so-called borderline symptoms are common and may have a dissociative aetiology 50 .

The average number of first rank symptoms reported by those with a dissociative disorder (3.5) is comparable to Sar et al.'s ${ }^{46}$ outpatient dissociative disorder sample (4.8), which was also assessed with the DDIS. A greater percentage of individuals with DID in Sar et al.'s sample is likely to account for their slightly higher score. As can be seen in Table I, Schneiderian first rank symptoms were commonly reported by five of the six individuals with DID and DDNOS. Yet, these same symptoms were experienced considerably less by those with amnesia and depersonalisation. Averaging the first rank symptoms experienced by those with DID and DDNOS (6.5) produces a figure nearly identical to those reported in other severe dissociative disorder samples (e.g., $6.4,{ }^{10}, 6.2,{ }^{48}$ ). The similar frequency of overall first rank symptoms reported by the dissociative and non-dissociative cohorts in this study may be a product of the low number of these symptoms reported by those with amnesia and depersonalisation. In addition, the non-dissociative group included individuals with psychotic illnesses. Moreover, this non-dissociative cohort reported significant histories of childhood abuse (see Table II), which has been related to Schneiderian first rank symptoms ${ }^{51}$. The significant history of childhood trauma may also account for the high average DES score in the non-dissociative group.

Studies of dissociative disorder frequency and prevalence have utilized as an inclusion-exclusion screening marker a DES score of 30 (e.g., ${ }^{46}$ ), 25 (e.g.. ${ }^{45,47}$ ) and $20^{18}$. However, the current study cautions against using such cut-offs in studies designed to detect dissociative disorders. Four participants with a dissociative disorder had DES scores below 30, while two were below 20 . Latz et al. ${ }^{52}$ have also demonstrated low DES scores in individuals with a dissociative disorder. Moreover, in the current study, four non-dissociative disorder participants had DES scores over 30. As well as dissociative symptoms being relatively common in many non-dissociative psychiatric illnesses, administration difficulties in psychiatric samples, as noted in one case here (See footnote in Table I), may produce inaccurate DES scores ${ }^{45}$. Consequently using a DES 
cut-off score as a screening marker may exclude from more rigorous assessment individuals with a dissociative disorder and include those not positive for a dissociative disorder ${ }^{23,53}$.

The current study utilized clinical rather than self-report symptom markers for thorough dissociative disorder assessment and found that well over half those assessed had a dissociative disorder. However, perhaps the most significant limitation of this method is the fact that by definition the inclusion criteria select only individuals with a significant mental illness history for thorough assessment. As a result individuals with a dissociative disorder who have only recently entered psychiatric services are excluded. Future studies may benefit from incorporating both symptom and clinical markers to identify those receiving thorough dissociative disorder assessment.

All individuals with a dissociative disorder reported some form of childhood abuse and neglect with only two of the 13 reporting no sexual or emotional abuse in their childhood. The high level of childhood interpersonal trauma in the dissociative group is consistent with findings in the literature, with large series studies report upwards of $80 \%$ of dissociative individuals with child abuse histories (e.g., ${ }^{9,54}$ ). At the risk of error due to the small sample size, statistical comparison was not warranted. Consequently meaningful differences between abuse and neglect history in the dissociative and nondissociative groups cannot be concluded. Yet, the data provide several observations for future followed up. Firstly, abuse and neglect did not clearly discriminate the dissociative and non-dissociative groups, suggesting a relationship between childhood trauma and complex clinical presentations. Secondly, considerably more adult trauma was reported by those in the dissociative dis- order group, highlighting pathological dissociation as a possible risk factor for traumatic stress (e.g., ${ }^{55}$ ).

\section{Conclusion}

Idividuals with a dissociative disorder, especially DID and DDNOS, often present with a complex psychiatric picture and a history of misdiagnoses ${ }^{9,28}$. As such, the inclusion criteria in the current study (i.e., psychiatrically complex, treatment resistant individuals with a history of several different diagnoses) was designed to selectively increase the likelihood of including in the assessment phase individuals with an undetected dissociative disorder. Thus a representative psychiatric sample was not drawn and little comment can be made regarding the prevalence of dissociative disorders in the Northern Irish psychiatric population. However, the current results indicate that 1) dissociative disorders are a clinical reality in Northern Ireland, even if their prevalence does turn out to be relatively low, 2) complex psychiatric presentations may represent a clinical indicator which heightens suspicion for dissociative disorders, and 3 ) the psychiatric symptom profiles of dissociative disorders in Northern Ireland are similar to those reported in the literature.

\section{References}

1. McIntee JM. Dissociative identity disorder in the UK: Competing ideologies in an historical and international context. $\mathrm{PhD}$ thesis submitted to the City University. 2003.

2. Myers FWH. The subliminal consciousness: The mechanism of hysteria. Proc Soc for Psychical Research 1893; 9: 2-25. 
3. Meares R. Intimacy and alienation: Memory, trauma and personal being. Hove, East Sussex: Brunner-Routledge; 2000.

4. Prince M. The development and genealogy of the Misses Beauchamp: A preliminary report of a case of multiple personality. Proceedings of the Society for Psychical Research 1900; 15: 466-483. Reproduced in Morton Prince: Psychotherapy and multiple personality: Selected essays. NG Hales (Ed). Harvard University Press, Cambridge MA, 1975.

5. Morton JH, Thoma E. A case of multiple personality. Am J Clin Hypnosis 1964; 6: 216-225.

6. Baker D, Hunter E, Lawrence E, Medford N, Patel M, Senior C, Sierra M, Lambert MV, Phillips ML, David AS. Depersonalisation disorder: Clinical features of 204 cases. Br J Psychiatry 2003; 182: 428-433.

7. Coons PM. Dissociative disorder not otherwise specified: a clinical investigation of 50 cases with suggestions for typology and treatment. Dissoc 1992; 5: 187-195.

8. Coons PM, Bowman ES, Milstein V. Multiple personality disorder: A clinical investigation of 50 cases. J Nerv Ment Disease 1988; 176: 519-527.

9. Middleton W, Butler J. Dissociative identity disorder: An Australian series. Aust NZ J Psychiatry 1998; 32: 794-804.

10. Ross CA, Miller SD, Reagor P, Bjornson L, Fraser GA, Anderson G. Structured interview data on 102 cases of multiple personality disorder from four centers. Am J Psychiatry 1990a; 147: 596-601.

11. Simeon D, Gross S, Guralnik O, Stein DJ, Schmeidler J, Hollander E. Feeling unreal: 30 cases of DSM-III-R depersonalization disorder. Am J Psychiatry 1997; 154 1107-1113.

12. Rifkin A, Ghisalbert DO, Dimatou S, Jin C, Sethi M. Dissociative identity disorder in psychiatric inpatients. Am J Psychiatry 1998; 155: 844-845.

13. Ross CA. Epidemiology of multiple personality disorder and dissociation. Psych Clinics N America 1991; 14: 503-517.

14. Akyüz G, Dogan O, Sar V, Yargiç LI, Tutkun H. Frequency of dissociative identity disorder in the general population in Turkey. Comp Psychiatry 1999; 40: 151-159.

15. Ross CA, Anderson G, Fleisher WP, Norton GR. The frequency of multiple personality disorder among psychiatric inpatients. Am J Psychiatry 1991; 148: 1717-1720.

16. Sar V, Akyüz G, Dogan O. Prevalence of dissociative disorders among women in the general population. Psychiat Res in press.
17. Friedl MC, Draijer N. Dissociative disorders in Dutch psychiatric inpatients. Am J Psychiatry 2000; 157: 1012-1031.

18. Gast U, Rodewald F, Nickel V, Emrich H. Prevalence of dissociative disorders among psychiatric inpatients in a German university clinic. J Nerv Ment Disease 2001; 189: 249-257.

19. Knudsen H, Draijer N, Haselrud J, Boe T, Boon S. Dissociative disorders in Norwegian psychiatric inpatients. Paper presented at the Spring meeting of the International Society for the Study of Dissociation. Amsterdam, The Netherlands 1995. Cited in CA Ross, Dissociative identity disorder: Diagnosis, clinical features, and treatment of multiple personality (2nd ed.). New York: Wiley; 1997.

20. Modestin J, Ebner G, Junghan M, Erni T. Dissociative experiences and dissociative disorders in acute psychiatric inpatients. Comp Psychiatry 1996; 37: 355-361.

21. Friedl MC, Draijer N, de Jonge P. Prevalence of dissociative disorders in psychiatric in-patients: The impact of study characteristics. Acta Psych Scandinavia 2000; 102: 423-428.

22. Coons PM. The dissociative disorders: Rarely considered and underdiagnosed. Psych Clinics N America 1998; 21: 637-648.

23. Steinberg M, Rounsaville B, Cicchetti D. Detection of dissociative disorders in psychiatric patients by a screening instrument and a structured diagnostic interview. Am J Psychiatry 1991; 148: 1050-1054.

24. Lewis CA, Dorahy MJ, Paterson MC, Mills H, O'Rawe B, Miller P. The absence of dedicated information on dissociative disorders in clinical psychology and psychiatry training programs in Ireland [Letter to the editor]. Irish J Psychol Med 2005; 22: 74-75.

25. Dell PF. Dissociative phenomenology of dissociative identity disorder. J Nerv Ment Disease 2002; 190: 10-15.

26. Dorahy MJ, Middleton W. Dissociative identity disorder and the complicated clinical presentation. Clinical Psychology 2002; 18: 35-41.

27. Nijenhuis ERS. Somatoform dissociation: Phenomena, measurement and theoretical issues. Assen: Van Gorcum; 1999.

28. Putnam FW, Guroff JJ, Silberman EK, Barban L, Post RM. The clinical phenomenology of multiple personality disorder: Review of 100 recent cases. J Clin Psychiatry 1986; 47: 285-293.

29. Kluft RP. First rank symptoms as a diagnostic clue to multiple personality disorder. Am J Psychiatry 1987; 144: 293-298.

30. Ross CA, Miller SD, Reagor P, Bjornson L, Fraser GA, Anderson G. Schneiderian symptoms in multiple per- 
sonality disorder and schizophrenia. Comp Psychiatry 1990b; 31: 111-118.

31. Coons PM, Milstein V. Psychosexual disturbances in multiple personality: Characteristics, eitology and treatment. J Clin Psychiatry 1986; 47: 106-110.

32. Schultz R, Braun BG, Kluft RP. Multiple personality disorder: Phenomenology of selected variables in comparison to major depression. Dissoc 1989; 2: 45-51.

33. Dorahy MJ, Lewis CA. Dissociative identity disorder in Northern Ireland: A survey of attitudes and experience among clinical psychologists and psychiatrists. J Nerv Ment Disease 2002; 190: 707-710.

34. Merskey $\mathrm{H}$. The manufacture of personalities: The production of multiple personality disorder. Br J Psychiatry $1992 ; 160: 327-340$.

35. Casey P. Multiple personality disorder. Prim Care Psychiatry 2001; 7: 7-11.

36. Dorahy MJ, Lewis CA, Mulholland CA. The detection of dissociative identity disorder by Northern Irish clinical psychologists and psychiatrists: A clinical vignettes study. Journal of Trauma and Dissociation, in press.

37. Ross CA, Heber S, Norton GR, Anderson D, Anderson G, Barchet P. The Dissociative Disorders Interview Schedule: A structured interview. Dissoc 1989; 2: 169-189.

38. Carlson EB, Putnam FW. An update on the dissociative Experiences Scale. Dissoc 1993; 6: 16-27.

39. Nijenhuis ERS, Spinhoven P, van Dyck R, Van der Hart O, Vanderlinden J. The development and psychometric characteristics of the Somatoform Dissociation Questionnaire (SDQ-20). J Nerv Ment Disease 1996; 184: 688-694.

40. Ross CA. The validity and reliability of dissociative identity disorder. In LM Cohen, JN Berzoff, MR Elin (Eds), Dissociative identity disorder: Theoretical and treatment controversies. Northvale, NJ: Aronson 1995; 65-84.

41. Waller NG, Putnam FW, Carlson EB. Types of dissociation and dissociative types. Psychol Methods 1996; 1: 300-321.

42. Carlson EB. Studying the interaction between physical and psychological states with the Dissociative Experiences Scale. In D Spiegel (Ed), Dissociation: Culture, mind, and body. Washington, DC: American Psychiatric Press, Inc. 1994; pp. 41-58.

43. Nijenhuis ERS, Spinhoven P, van Dyck R, Van der Hart O, Vanderlinden J. Psychometric properties of the Somatoform Dissociation Questionnaire: A replication study. Psychother Psychosomatics 1998; 67: 17-23.

44. Putnam FW, Loewenstein RJ, Silberman EJ, Post RM. Multiple personality in a hospital setting. J Clin Psychiatry $1984 ; 45:$ 172-175.
45. Horen SA, Leichner PP, Lawson JS. Prevalence of dissociative symptoms and disorders in an adult psychiatric inpatient population in Canada. Canad J Psychiatry 1995; 40: 185-191.

46. Sar V, Tutkun H, Alyanak B, Bakim B, Baral I. Frequency of dissociative disorders among psychiatric outpatients in Turkey. Comp Psychiatry 2000; 41: 216-222.

47. Saxe GN, Van der Kolk BA, Berkowitz R, Chinman G, Hall K, Lieberg G, Schwartz J. Dissociative disorders in psychiatric inpatients. Am J Psychiatry 1993; 150: 10371042 .

48. Sar V, Yargic I, Tutkun H. Structured interview data on 35 cases of dissociative identity disorder in Turkey. Am J Psychiatry 1996; 153: 1329-1333.

49. Sar V, Kundakci T, Kiziltan E, Yargic IL, Tutkun H, Bakim B, Bozkurt O, Özpulat T, Keser, V, Özdemir Ö. The Axis I dissociative disorder comorbidity of borderline personality disorder among psychiatric outpatients. J Trauma Dissociat 2003; 4: 119-136.

50. Steele K, Van der Hart O, Nijenhuis ERS. Allgemeine Behandlungsstrategien komplexer dissoziativer Störungen [General treatment strategies for complex dissociative disorders]. In A Eckhart-Henn, SO Hoffman (Eds), Dissoziative Störungen des Bewußtseins [Dissociative disorders of consciousness]. Stuttgart: Schatterauer-Verlag 2004; 357-394.

51. Ross CA, Anderson G, Clark P. Childhood abuse and the positive symptoms of schizophrenia. Hosp Comm Psychiatry 1995; 45: 489-491.

52. Latz TT, Kramer SI, Hughes DL. Multiple personality disorder among female inpatients in a State hospital. Am J Psychiatry 1995; 152: 1343-1348.

53. Carlson EB, Putnam FW, Ross CA, Torem M, Coons P, Dill DL, Loewenstein RJ, Braun BG. Validity of the Dissociative Experiences Scale in screening for multiple personality disorder: A multicenter study. Am J Psychiatry $1993 ; 150: 1030-1036$.

54. Ross CA, Norton GR, Wozney K. Multiple personality disorder: An analysis of 236 cases. Canad J Psychiatry 1989; 34: 413-418.

55. Kluft RP. Dissociation and subsequent vulnerability: A preliminary study. Dissoc 1990; 3: 167-173.

Address for correspondence:

Martin Dorahy

School of Psychology

The Queen's University of Belfast

Belfast, BT9 5BP

Northern Ireland.

Email: m.dorahy@qub.ac.uk; phone: +44 2890566199

IRELAND 